\title{
Functional integrity of the habenula is necessary for social play behaviour in rats
}

\author{
Linda W. M. van Kerkhof, ${ }^{1}$ Ruth Damsteegt, ${ }^{1}$ Viviana Trezza, ${ }^{1,2}$ Pieter Voorn ${ }^{3}$ and Louk J. M. J. Vanderschuren ${ }^{1,4}$ \\ ${ }^{1}$ Department of Neuroscience and Pharmacology, Brain Center Rudolf Magnus, University Medical Center Utrecht, Utrecht, The \\ Netherlands \\ ${ }^{2}$ Department of Sciences, Section of Biomedical Sciences and Technologies, University "Roma Tre", Rome, Italy \\ ${ }^{3}$ Department of Anatomy and Neurosciences, Neuroscience Campus Amsterdam, VU University Medical Centre, Amsterdam, \\ The Netherlands \\ ${ }^{4}$ Department of Animals in Science and Society, Division of Behavioural Neuroscience, Faculty of Veterinary Medicine, Utrecht \\ University, Yalelaan 2, 3584 CM Utrecht, The Netherlands
}

Keywords: adolescence, c-fos, habenula, social behaviour, social isolation

\begin{abstract}
During post-weaning development, a marked increase in peer-peer interactions is observed in mammals, including humans, which is signified by the abundance of social play behaviour. Social play is highly rewarding, and known to be modulated through monoaminergic neurotransmission. Recently, the habenula has received widespread attention because of its role in the regulation of monoaminergic neurotransmission as well as in a variety of emotional and cognitive functions. Therefore, in the present study, we investigated the involvement of the habenula in social play behaviour. Using the neuronal activity maker c-fos, we showed that the habenula was activated after $24 \mathrm{~h}$ of social isolation in adolescent rats, and that a subsequent social play interaction reduced c-fos activity in the medial part of the lateral habenula. This suggested that habenula activity modulated the aversive properties of social isolation, which was alleviated by the positive effects of social play. Furthermore, after functional inactivation of the habenula, using a mixture of the GABA receptor agonists baclofen and muscimol, social play behaviour was markedly reduced, whereby responsiveness to play solicitation was more sensitive to habenula inactivation than play solicitation itself. Together, our data indicate an important role for the habenula in the processing of positive (i.e. social play behaviour) and negative (i.e. social isolation) social information in adolescent rats. Altered habenula function might therefore be related to the social impairments in childhood and adolescent psychiatric disorders such as autism, attention deficit/hyperactivity disorder and early-onset schizophrenia.
\end{abstract}

\section{Introduction}

Social play behaviour is a characteristic, vigorous form of social interaction in young mammals (Panksepp et al., 1984; Vanderschuren et al., 1997; Spear, 2000; Pellis \& Pellis, 2009). Social play behaviour is highly rewarding (Vanderschuren, 2010; Trezza et al., 2011a) and is thought to be important for the acquisition of communicative skills, the formation and maintenance of social bonds, and social and cognitive development (Potegal \& Einon, 1989; Van den Berg et al., 1999; Špinka et al., 2001; Palagi, 2006; Pellis \& Pellis, 2009; Baarendse et al., 2013). Conversely, abnormalities in social play behaviour have been observed in several child and adolescent psychiatric disorders (Alessandri, 1992; Moller \& Husby, 2000; Jordan, 2003; Manning \& Wainwright, 2010). Despite its importance for behavioural development and its impairment in several child and adolescent psychiatric disorders, our knowledge of the neural underpinnings of social play behaviour is limited (Panksepp et al., 1984; Vanderschuren et al.,

Correspondence: Louk J. M. J. Vanderschuren, ${ }^{4}$ Department of Animals in Science and Society, as above.

E-mail: 1.j.m.j.vanderschuren@uu.nl

Received 26 May 2013, accepted 8 August 2013
1997; Trezza et al., 2010; Siviy \& Panksepp, 2011). Therefore, identifying the neural substrates of social play behaviour will advance our understanding of normal social development as well as the aetiology of child and adolescent psychiatric disorders.

Lesion and intracranial drug administration studies have implicated the frontal cortex (Panksepp et al., 1994; Schneider \& Koch, 2005; Pellis et al., 2006; Bell et al., 2009; van Kerkhof et al., 2013a), as well as the thalamus (Siviy \& Panksepp, 1985, 1987), amygdala (Meaney et al., 1981; Daenen et al., 2002; Trezza et al., 2012), striatum (Pellis et al., 1993; van Kerkhof et al., 2013a) and nucleus accumbens (Trezza et al., 2011b, 2012; van Kerkhof et al., 2013a) in social play. Furthermore, monoaminergic (i.e. dopaminergic, serotonergic and noradrenergic) neurotransmission plays a prominent role in the modulation of social play (Siviy et al., 1996, 2011; Vanderschuren et al., 1997, 2008; Homberg et al., 2007; Trezza et al., 2010; Siviy \& Panksepp, 2011).

In recent years, the habenula has received a great deal of attention because of its key role in the modulation of monoaminergic neurotransmission (Lecourtier \& Kelly, 2007; Hikosaka, 2010). Monoamine nuclei, including the ventral tegmental area (VTA), dorsal raphe nucleus, and locus coeruleus, receive regionally distributed 
input from distinct habenular subregions (Lecourtier \& Kelly, 2007; Kim, 2009; Goncalves et al., 2012). Considering its interconnections with monoaminergic pathways, it is not surprising that the habenula has been implicated in functions that depend on monoaminergic signalling, such as reward, punishment, decision-making, learning, attention and stress (for reviews see Hikosaka, 2010; Lecourtier \& Kelly, 2007). Furthermore, the habenula has been suggested to be involved in several psychiatric disorders that involve altered monoaminergic neurotransmission, including depression, attention deficit/hyperactivity disorder, and schizophrenia (Yang et al., 2008; Hikosaka, 2010; Lee \& Goto, 2011).

Given its involvement in a variety of cognitive, emotional and behavioural processes, it is reasonable to expect that the habenula is also involved in social behaviour. However, there is only sparse information about the role of the habenula in social interaction (Modianos et al., 1974; Matthews-Felton et al., 1995; Lecourtier et al., 2004). The present study addresses this issue by mapping habenula neuronal activity during social isolation and social play behaviour, and determining the effects of inhibition of habenula activity on the structure and quantity of social play behaviour.

\section{Materials and methods}

\section{Animals}

Male Wistar rats (Charles River, Sulzfeld, Germany) arrived in our animal facility at 21 days of age. They were housed in groups of four in Macrolon cages $(40 \times 26 \times 20 \mathrm{~cm})$ under controlled conditions (i.e. temperature of $20-21{ }^{\circ} \mathrm{C}, 55-65 \%$ relative humidity and $12 / 12 \mathrm{~h}$ light cycle with lights on at $07.00 \mathrm{~h}$ ). Food and water were available ad libitum. All animals used were experimentally naive. Before the start of the experiment, the rats were handled at least twice. All experiments were approved by the Animal Ethics Committee of Utrecht University and were conducted in accordance with Dutch regulations (Wet op de Dierproeven, 1996) and European regulations (Guideline 86/609/EEC).

\section{Surgical procedures}

The surgical procedures were based on previous experiments (Trezza et al., 2011b, 2012; van Kerkhof et al., 2013a). At 2728 days of age, rats were anaesthetized with Hypnorm $(0.08 \mathrm{~mL} /$ $100 \mathrm{~g}$, s.c.) $(0.315 \mathrm{mg} / \mathrm{mL}$ fentanylcitrate and $10 \mathrm{mg} / \mathrm{mL}$ fluanison, Janssen, Beerse, Belgium) and positioned in a stereotactic frame (David Kopf Instruments, Tujunga, CA, USA). Guide cannulas (24 gauge microblasted thin-walled stainless steel; Cooper's Needleworks, Birmingham, UK) were implanted bilaterally. The cannulas were aimed $0.5 \mathrm{~mm}$ above the habenula (coordinates: anterior-posterior, $-3.0 \mathrm{~mm}$ from Bregma; medial-lateral, $\pm 0.8 \mathrm{~mm}$ from midline; dorsal-ventral, $-4.2 \mathrm{~mm}$ from skull surface). Coordinates were determined by pilot placements in rats at 28 days of age.

Cannulas were secured with stainless steel screws and dental acrylic. Stainless steel stylets (29 gauge) were inserted into the guide cannulas to maintain patency. After surgery, rats were individually housed for 4 days to recover, after which they were housed with their original cage mates.

\section{Drugs and infusion procedures}

The GABA-A receptor agonist muscimol (Tocris Bioscience, Bristol, $\mathrm{UK}$ ) and the GABA-B receptor agonist (RS)-baclofen (Tocris Bioscience) were dissolved in saline. Infusion procedures were as previously described (Trezza et al., 2011b, 2012; van Kerkhof et al., 2013a). In short, bilateral infusions of drugs or an equivalent volume of saline were administered using 30 gauge injectors (Bilaney, Düsseldorf, Germany) that were connected to $10 \mu \mathrm{L}$ Hamilton microsyringes by polyethylene (PE-20) tubing. Over $60 \mathrm{~s}, 0.3 \mu \mathrm{L}$ of the drugs or saline was infused using a syringe pump (Harvard Apparatus, Holliston, MA, USA), and the injectors were left in place for another $60 \mathrm{~s}$ to allow for diffusion. Two different doses were used: a mixture of $1.0 \mathrm{nmol} /$ $0.3 \mu \mathrm{L}$ baclofen and $0.1 \mathrm{nmol} / 0.3 \mu \mathrm{L}$ muscimol or a mixture of $0.3 \mathrm{nmol} / 0.3 \mu \mathrm{L}$ baclofen and $0.03 \mathrm{nmol} / 0.3 \mu \mathrm{L}$ muscimol (B\&M). Stylets were replaced after the procedure.

\section{Behavioural testing}

Experiments were performed as previously described (Trezza \& Vanderschuren, 2008a,b; Vanderschuren et al., 2008), in a soundattenuated chamber under red light conditions. The testing arena was a Plexiglas cage $(40 \times 40 \times 60 \mathrm{~cm})$ with approximately $2 \mathrm{~cm}$ of wood shavings covering the floor. Animals were randomly paired with an unfamiliar partner, i.e. not a cage mate. Animals in a test pair did not differ by more than $10 \mathrm{~g}$ in body weight.

The experiment investigating the effect of functional inactivation of the habenula on social play behaviour was conducted as follows (Trezza et al., 2011b, 2012; van Kerkhof et al., 2013a). At 1 week post-surgery, the rats were habituated to the experimental procedures on two consecutive days. On the first habituation day, rats were individually placed into the test cage for $10 \mathrm{~min}$. On the second habituation day, the animals were socially isolated for $2.5 \mathrm{~h}$. Pairs of rats were then infused with vehicle solutions and placed into the test cage for $15 \mathrm{~min}$, to habituate them to the infusion and testing procedures. On the test day, pairs of rats were isolated for 3.5 or $24 \mathrm{~h}$. Both rats in a pair were then simultaneously infused, placed into separate holding cages for $5 \mathrm{~min}$ and subsequently placed together into the test cage for $15 \mathrm{~min}$.

The experiment aimed to determine the c-fos expression in the habenula after social play behaviour was performed as previously described (van Kerkhof et al., 2013b). Animals were separately habituated to the test cage for $30 \mathrm{~min}$ on four consecutive days, to minimize the influence of novelty of the test environment on c-fos expression. The motivation for play was enhanced to half-maximal and maximal levels, respectively, by isolating the animals for 3.5 or $24 \mathrm{~h}$ before the test (Niesink \& Van Ree, 1989; Vanderschuren et al., $1995,2008)$. On the test day, animals were placed into the test cage either in pairs ('play group') or alone ('no play group') for $15 \mathrm{~min}$. After the test, animals were placed back into their separate cages for $30 \mathrm{~min}$. Subsequently, rats were killed by decapitation, and their brains were quickly removed and frozen immediately $\left(-80^{\circ} \mathrm{C}\right)$.

The behaviour of the animals was recorded using a camera with zoom lens, video tape recorder and television monitor. The behaviour of the playing rats was assessed using Observer 5.1 software (Noldus Information Technology B.V., Wageningen, The Netherlands). The structure of social play behaviour in rats has previously been described in detail (Baenninger, 1967; Bolles \& Woods, 1964; Panksepp \& Beatty, 1980; Pellis \& Pellis, 1987; Pellis et al., 1989; Poole \& Fish, 1975; for reviews see Panksepp et al., 1984; Pellis \& Pellis, 1998; Trezza et al., 2010; Vanderschuren et al., 1997). In rats, a bout of social play behaviour starts with one rat soliciting ('pouncing') another animal, by attempting to nose or rub the nape of its neck. The animal that is pounced upon can respond in different ways. If the animal that is pounced upon responds by evading, the soliciting rat may start to chase it, thus making another attempt to launch a play bout. The solicited animal may also rear towards the 
soliciting animal and the two animals may rapidly push, paw, and grab each other ('boxing'). If the animal that is pounced upon fully rotates to its dorsal surface, 'pinning' is the result, i.e. one animal lying with its dorsal surface on the floor with the other animal standing over it. From this position, the supine animal can initiate another play bout, by trying to gain access to the other animal's neck. Thus, during social play, pouncing is considered an index of play solicitation, whereas pinning functions as a releaser of a prolonged play bout (Poole \& Fish, 1975; Panksepp \& Beatty, 1980; Pellis \& Pellis, 1987; Pellis et al., 1989). Pinning and pouncing frequencies can easily be quantified and are considered the most characteristic parameters of social play behaviour in rats (Panksepp \& Beatty, 1980). During the social encounter, animals may also display social behaviours not directly associated with play, such as sniffing or grooming the partner's body (Panksepp \& Beatty, 1980; Vanderschuren et al., 1995, 2008). As social play behaviour in rats strongly depends on the playfulness of the partner (Pellis \& McKenna, 1992; Trezza \& Vanderschuren, 2008a), in the present study, both animals in a play pair were similarly treated. The following parameters were therefore scored per pair of animals (to determine the effect of B\&M treatment) or individually (for c-fos analysis).

Social behaviours related to play:

- Frequency of pinning.

- Frequency of pouncing.

- Total play duration: the total amount of time spent in playful social interactions (i.e. pinning, pouncing, boxing or chasing the play partner).

Social behaviours unrelated to play:

- Time spent in social exploration: the total amount of time spent in non-playful forms of social interaction (i.e. one animal sniffing or grooming any part of the partner's body).

Pinning, pouncing and other playful behaviours usually occur very rapidly and are of short duration. Therefore, scoring their individual frequency is more informative than scoring their duration. Moreover, we have also found that pinning and pouncing are very reliable play parameters, which occur consistently and with considerable frequency during playful encounters (see also Panksepp \& Beatty, 1980; Vanderschuren et al., 1995, 2008), whereas the occurrence of chasing and boxing can be quite variable. In order to evaluate the total amount of time spent in playful social behaviours (e.g. pinning, pouncing) vs. social behaviours unrelated to play (e.g. social exploration: sniffing, social grooming), we also included the total play duration as a parameter. Changes in boxing and chasing provided only minor contributions to the effects on total play duration observed.

To assess whether the effects of the drug treatment on social play were secondary to changes in locomotor activity, the rats were subsequently tested for horizontal locomotor activity as previously described (Trezza et al., 2009; Veeneman et al., 2011; van Kerkhof et al., 2013a). There was at least 1 day without infusions or testing between the tests for social play behaviour and locomotor activity. The infusion protocol was similar to that described above. After the infusion procedure, rats were transferred to a plastic cage $(1 \times \mathrm{w} \times \mathrm{h}, 50 \times 33 \times 40 \mathrm{~cm})$ and their position was tracked five times per second for $30 \mathrm{~min}$ using a video-tracking system (EthoVision; Noldus Information Technology B.V.).

\section{Histological confirmation of injection sites}

Animals were killed using carbon dioxide inhalation and microinjected with $0.3 \mu \mathrm{L}$ of black ink (Parker) for 1 min through the guide cannulas, similar to the drug infusion procedure. After the infusion, animals were immediately decapitated and their brains removed and immediately frozen. Cryostat sections $(20 \mu \mathrm{m})$ were collected and stained using Nissl staining. In short, slides were placed in Thionin solution $(0.13 \%$ in MilliQ) for $1-5 \mathrm{~min}$. Subsequently, slides were placed for $1 \mathrm{~min}$ in MilliQ water, 70, 80, 96 and 100\% ethanol $(3 \times)$. Next, slides were placed in xylene $(2 \times)$ for 2 min and coverslipped using Entellan (Merck, Darmstadt, Germany). Placement of the microinjection sides was determined using a light microscope according to the atlas of Paxinos \& Watson (2007). Only pairs in which both animals had bilateral needle tracks terminating in the habenula were included in the final analysis. A schematic representation of brain sections with the spread of microinjection placements is presented in Fig. 1A. Infusion sites included both the medial $(\mathrm{mHb})$ and lateral $(\mathrm{Hb})$ habenula (see Fig. 1B for a diagram outlining the different habenula subnuclei).

\section{c-fos digoxigenin in situ hybridization}

Fresh frozen brains were cryostat sectioned $\left(-20^{\circ} \mathrm{C}\right)$ at $14 \mu \mathrm{m}$, mounted on Super-Frost Plus slides (Eric Scientific Co., Portsmouth, $\mathrm{NH}$, USA) and stored at $-80{ }^{\circ} \mathrm{C}$. Slides were warmed to room temperature $\left(19-21^{\circ} \mathrm{C}\right)$ before fixation with $4 \%$ paraformaldehyde [4\% paraformaldehyde in phosphate-buffered saline, $154 \mathrm{~mm} \mathrm{NaCl}$, $0.896 \mathrm{~mm} \mathrm{KH}_{2} \mathrm{PO}_{4}, 4.58 \mathrm{~mm} \mathrm{Na} \mathrm{HPO}_{4}, \mathrm{pH}$ 7.5]. Acetylation of the slides was performed with acetic anhydride $(0.25 \%$ acetic anhydride in $1.5 \%$ triethanolamine buffer). Subsequently, slides were washed with phosphate-buffered saline and $2 \times$ saline sodium citrate buffer before applying the hybridization mix (50\% formamide, $4 \times$ saline sodium citrate buffer, $0.4 \%$ baker's yeast tRNA, $2 \% 50 \times$ Denhardt's reagent, $10 \%$ Dextran, $0.05 \%$ salmon sperm DNA) containing $5 \mathrm{ng}$ c-fos probe per section.

The probe was generated using cDNA synthesized from total rat brain RNA and the iScript reverse transcriptase kit with random hexamers, according to the manufacturer's protocol (Bio-Rad, Hercules, CA, USA). A polymerase chain reaction was performed with

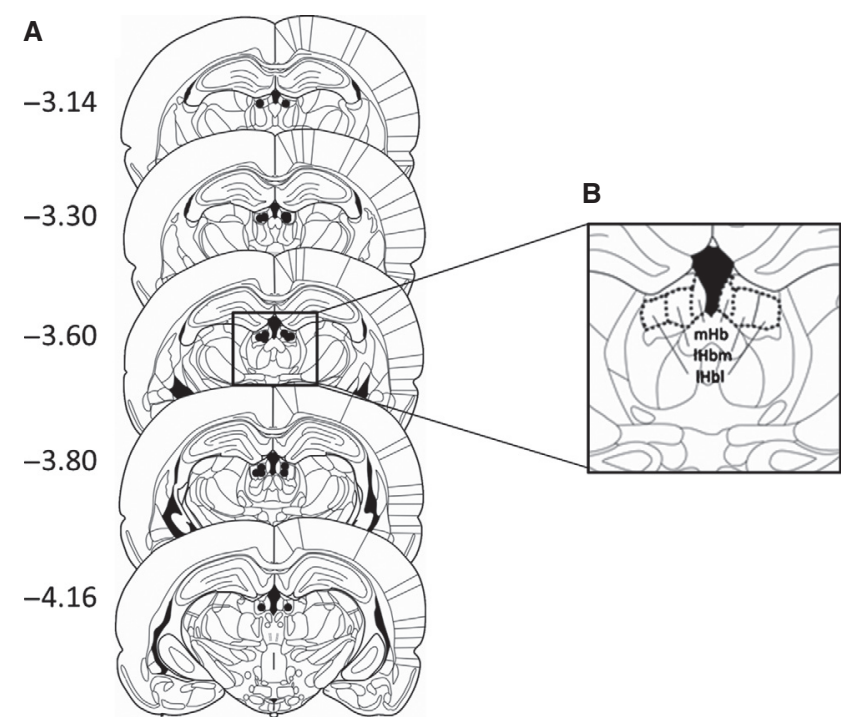

FIG. 1. (A) Schematic representation of brain sections with the spread of microinjection placements (black dots) in the habenula. (B) Schematic representation of a brain section outlining the borders of the different habenula subnuclei analysed for c-fos expression. Adapted from Paxinos \& Watson (2007). 
c-fos-specific primers containing T3/T7 promoters. Primers (Eurogentec, Liège, Belgium) were designed using Primer3 (Rozen \& Skaletsky, 2000). All primers were checked for gene specificity by BLAST searching. The primer sequences used for c-fos (Genbank NM_022197.2) were T3 antisense: AATTAACCCTCACTAAAGG G-CACAGCCTGGTGAGTTTCAC and T7 sense: GTAATACGAC TCACTATAGGG-TCACCCTGCCTCTTCTCAAT. The polymerase chain reaction product size was checked by agarose gel electrophoresis. From these polymerase chain reaction products, labelled probes were generated by linear amplification using the MAXIscript kit according to the manufacturer's protocol (Applied Biosystems, Foster City, CA, USA) and probes were labelled using digoxigenin (DIG)UTP (DIG labelling mix; Roche, Penzberg, Germany). The probe size and concentration were checked using agarose gel electrophoreses. The probe was briefly heated at $95{ }^{\circ} \mathrm{C}$ before adding it to the hybridization mix and hybridization was performed in a humid chamber at $60{ }^{\circ} \mathrm{C}$ overnight. Method specificity control included hybridization with the sense probe, which did not result in specific cell labelling, as illustrated in Fig. 2A (the image contrast in this figure was enhanced using Corel Photo-Paint).

Post-hybridization washes were carried out with $1 \times$ saline sodium citrate buffer at $60{ }^{\circ} \mathrm{C}$, including a wash with $2 \times$ saline sodium citrate buffer containing RNAse A ( 0.3 units $/ \mathrm{mL}$; Roche) at $37{ }^{\circ} \mathrm{C}$. Before antibody incubation, slides were exposed to a blocking solution (1\% blocking powder in Tris buffer, $100 \mathrm{~mm}$ Tris, $150 \mathrm{~mm} \mathrm{NaCl}, \mathrm{pH}$ 7.5) according to the DIG detection kit manual (Roche) for $1 \mathrm{~h}$. Slides were incubated with anti-DIG-alkaline phosphatase antibody (1:2500, DIG detection kit; Roche). This antibody was conjugated to alkaline phosphatase, allowing the use of nitro-blue tetrazoliumchloride/5-bromo-4-chloro-3-indolyphosphate p-toluidine salt as a substrate to visualize the probe. The antibody incubation was performed overnight at $4{ }^{\circ} \mathrm{C}$.

Following antibody incubation, slides were washed in Trisbuffered saline (100 mM Tris, $150 \mathrm{~mm} \mathrm{NaCl}, \mathrm{pH} 7.5)$ and a magnesium buffer (100 mм Tris, $100 \mathrm{~mm} \mathrm{NaCl}, 50 \mathrm{~mm} \mathrm{MgCl}, \mathrm{pH}$ 9.5). Incubation with the substrate nitro-blue tetrazoliumchloride/5bromo-4-chloro-3-indolyphosphate p-toluidine salt (1:50; Roche) in magnesium buffer was performed in a humid chamber at room temperature for $28 \mathrm{~h}$. The reaction was stopped with Tris-buffered saline containing $1 \mathrm{~mm}$ EDTA $(\mathrm{pH} 7.5)$ and slides were washed twice with water to remove salt precipitate. Slides were left to dry and coverslipped using Merckoglas (Merck).

\section{Quantification of c-fos-immunopositive cells}

The quantification methods have been described previously (Nordquist et al., 2008). Images of all regions of interest were digitized using an objective magnification of $\times 5$ on a Leica DM/RBE photomicroscope with a Q-imaging 12 bit camera and MCID software (InterFocus Imaging, Cambridge, UK). Image acquisition was preceded by a flat field correction and a calibration routine to ensure standardized optical density values. For each subject, three (occasionally two) sections were digitized per region of interest. Sections were made in series of 10 and therefore sections were $140 \mu \mathrm{m}$ apart.

Regions of interest were determined using images of Nissl-stained adjacent sections (Nissl staining as described above) according to the atlas of the rat brain by Paxinos \& Watson (2007), as schematically presented in Fig. 1B. The habenula can be divided into the $\mathrm{mHB}$ and $\mathrm{lHb}$, whereby the latter can be subdivided into the lateral habenula medial part $(1 \mathrm{Hbm})$ and lateral habenula lateral part $(\mathrm{lHbl})$. These regions provide regionally distributed input to monoamine nuclei, including the VTA, dorsal raphe nucleus, and locus coeruleus (Lecourtier \& Kelly, 2007; Kim, 2009; Goncalves et al., 2012). Therefore, c-fos-immunopositive cells were quantified in these three subregions of the habenula. An algorithm was used to identify c-fos-positive cells (Nordquist et al., 2008). The c-fos-immunopositive cell somata were segregated from background staining using several point operators and spatial filters combined in an algorithm designed to detect local changes in optical density. Images underwent histogram equalization followed by smoothing (low-pass filter, kernel size $7 \times 7$ ). Next, the unfiltered image was subtracted from the smoothed image. Subsequent steps involved optimizing the image for use as a measuring template; the image was binarized and subjected to erosion (kernel size $5 \times 5$ ), smoothing (kernel size $7 \times 7$ ) and dilation (kernel size $3 \times 3$ ). Finally, for detecting objects, the size and shape of c-fos-immunoreactive neuron exclu-
A

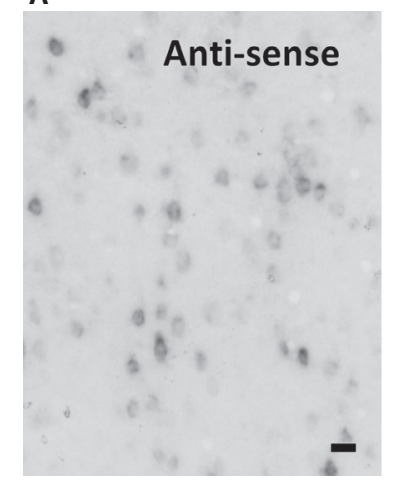

B

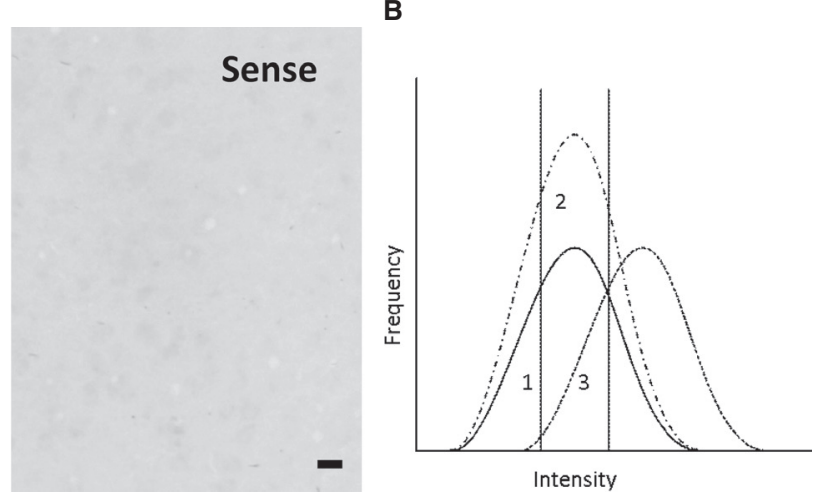

FIG. 2. (A) Illustration of immunolabelling using antisense or sense probes for c-fos in the motor cortex, a brain region with very high levels of c-fos gene expression. Note the presence and absence of specific cell labelling after hybridization with the antisense or sense probes, respectively. Bar $=50 \mu \mathrm{m}$. (B) Theoretical representation of potential shifts in the intensity histogram. Curve 1 indicates the frequency histogram of the control group. The two vertical lines indicate the cut-off points used to separate the cells into the light, medium and dark categories (33 and $67 \%$ ). The area under the curve represents the total number of c-fos-positive cells $/ \mathrm{mm}^{2}$, i.e. the cell density. If social play behaviour induces c-fos activity in a new group of neurons, an increase in the cell density is expected, which would be reflected in an upward shift of the histogram (curve 2). This should be apparent as an enhanced cell density primarily in the medium category. Alternatively, if the same neurons are active, but express more c-fos as a result of play behaviour, a rightward shift is expected, with an increase in the cell density in the dark category (curve 3). A downward or leftward shift in the histogram could be explained in a similar fashion. Adapted from Nordquist et al. (2008). 
sion criteria were used so that only objects with a surface area larger than $8 \mu \mathrm{m}^{2}$, maximum diameter smaller than $8 \mu \mathrm{m}$ and a form factor smaller than 0.9 were selected. The number of cells counted was corrected with a factor indicating the approximate size of a cell, thus preventing two adjacent segmented objects being mistakenly counted as one cell. This algorithm allowed for an observer-independent measurement. Several parameters were measured: number of c-fos-positive cells, optical density of each cell, and total measured surface area of the region.

\section{Data analysis of c-fos expression levels}

The parameters obtained from the MCID software were used to calculate the density of c-fos-positive cells (number of positive cells divided by the total surface area of the region). Changes in the (re) activity of a particular brain region upon exposure to a stimulus such as social play not only comprise changes in the number of responsive cells, but also the intensity with which individual cells respond. This intensity can be measured at the cellular level by determining the relative amount of hybridized probe in hybridization histochemistry, which represents the amount of mRNA (Higo et al. 1999; Hill et al. 1993; Robbins et al. 1991; Stylianopoulou et al. 2012; Zhao et al. 2008). In the present experiments, we used densitometry to measure the immunocytochemical signal that was used to detect the hybridized c-fos antisense probe. This signal consisted of the purple-brown reaction product generated by alkaline phosphatase in the protocol for detecting DIG-labelled probes as described in Materials and methods.

To compare the c-fos-positive cell density (FpCD) in a manner that takes the labelling intensity into account, cells were categorized into three conditions: light, medium, and dark. Therefore, a frequency histogram of the optical densities of all cells in the non-playing animals was made for each brain region. These histograms were used to calculate the 33rd and 67th percentile of the optical density in the non-playing animals. These optical density values were used to categorize the cells in all animals. The number of cells in each category was divided by the total surface area of the respective region of interest, to determine the cell density per intensity category. The cell densities of the three categories indicated shifts in the frequency histograms of the optical densities (Fig. 2B). An upward shift in the histogram would be reflected by an increase in the overall cell density as well as an increase in the medium category and would suggest recruitment of a new population of cells. A rightward shift of the curve is expected when the same neurons are active, but express more c-fos. This would be reflected by an increase in the cell density in the dark category. In a similar fashion, a downward or leftward shift of the histogram would indicate a smaller number of activated cells, or a reduced quantity of c-fos expression per activated cell, respectively.

\section{Statistical analysis}

For data analysis, SPSs software 15.0 (IBM Software, New York, NY, USA) was used. For each animal the mean FpCD of three images (taken from three subsequent sections) was calculated. To assess the effect of isolation time and play experience on the FpCD, data were analysed using a two-way ANOvA with social isolation and play experience as between-subject factors. To determine the effect of play on the FpCD per intensity category, a two-way ANOvA was also used, with play experience and social isolation time as between-subject factors, followed by post-hoc Student's $t$-test analysis if appropriate. To assess the effect of B\&M infusions on social play behaviour, data were analysed using a paired-samples Student's $t$-test or an independent Student's $t$-test, depending on the experimental setup. The effect of B\&M administration on locomotor activity was analysed using a one-way ANOVA.

\section{Results}

\section{Social isolation induces c-fos expression in the habenula}

The mean FpCD was determined in rats $(n=8 /$ group) that were socially isolated for 3.5 or $24 \mathrm{~h}$. After these isolation periods, half of the animals were placed in the test cage with a partner for $15 \mathrm{~min}$ ('play' group), whereas the other group was placed in the same test cage alone ('no play' group). Representative pictures of c-fos labelling in all groups are provided in Fig. 3A-D. In all habenula subregions, social isolation for $24 \mathrm{~h}$ induced a significant increase in the FpCD compared with social isolation for $3.5 \mathrm{~h} \quad[\mathrm{mHb}$ : $F_{\text {isolation }}(1,28)=2.522, P=0.026 ; 1 \mathrm{Hbm}: F_{\text {isolation }}(1,28)=33.524$, $P<0.001$; $\left.1 \mathrm{Hbl}: F_{\text {isolation }}(1,28)=22.556, P<0.001\right]$ (Fig. $3 \mathrm{E}-\mathrm{G}$ ). These results indicate that, after social isolation for $24 \mathrm{~h}$, c-fos activity was increased in the entire habenula. No effect of play on the FpCD was observed in any of the habenula regions $\left[\mathrm{mHb}: F_{\text {play }}\right.$ $(1,28)=0.013, P=0.910 ; 1 \mathrm{Hbm}: F_{\text {play }}(1,28)=1.337, P=0.257$; 1Hbl: $\left.\quad F_{\text {play }}(1,28)=1.167, \quad P=0.289\right]$, nor was an interaction observed between isolation and play $\left[\mathrm{mHb}: F_{\text {play } \times \text { isolation }}\right.$ $(1,28)=2.780, \quad P=0.107 ; \quad 1 \mathrm{Hbm}: \quad F_{\text {play }} \times$ isolation $(1,28)=1.912$, $P=0.178$; lHbl: $\left.F_{\text {play } \times \text { isolation }}(1,28)=1.101, P=0.303\right]$.

In addition, the c-fos expression levels were analysed taking the intensity levels into account (Fig. 4). This entailed the differentiation of the FpCD per category of intensity: light, medium and dark cells (see Fig. 2B). The results indicate that, in all regions, $24 \mathrm{~h}$ of social isolation decreased the FpCD in the light category $[\mathrm{mHb}$ : $F_{\text {isolation }}(1,27)=71.539, P<0.001 ; 1 \mathrm{Hbm}: F_{\text {isolation }}(1,28)=28.479$, $\left.P<0.001 ; 1 \mathrm{Hbl}: F_{\text {isolation }}(1,28)=32.231, P<0.001\right]$, whereas it increased the $\mathrm{FpCD}$ in the medium and dark categories [medium: $\mathrm{mHb}: F_{\text {isolation }}(1,27)=63.848, P<0.001 ; 1 \mathrm{Hbm}: F_{\text {isolation }}(1,28)=$ 38.411, $P<0.001$; 1Hbl: $F_{\text {isolation }}(1,28)=29.267, P<0.001$; dark: mHb: $\quad F_{\text {isolation }}(1,28)=49.644, \quad P<0.001 ; \quad 1 \mathrm{Hbm}: \quad F_{\text {isolation }}$ $(1,28)=104.981, P<0.001 ; 1 \mathrm{Hbl}: F_{\text {isolation }}(1,28)=38.210, P<$ 0.001] (Fig. 4). These results suggest that social isolation for $24 \mathrm{~h}$ enhanced the levels of c-fos in cells that already express c-fos as well as recruiting previously inactive cells.

Interestingly, in the $1 \mathrm{Hbm}$, a significant effect of play was observed in the dark category $\left[F_{\text {play }}(1,28)=4.348, P=0.046\right]$, as well as an interaction between the effect of play and the effect of isolation $\left[F_{\text {isolation }} \times\right.$ play $\left.(1,28)=4.943, P=0.034\right]$ (Fig. 4F). These results indicate that play had a differential effect on the dark c-fospositive cells in the $1 \mathrm{Hbm}$ after 3.5 and $24 \mathrm{~h}$ of isolation. Post-hoc independent $t$-tests showed that there was no effect of play after $3.5 \mathrm{~h}$ isolation $(t=0.381$, d.f. $=14, P=0.709)$, whereas after $24 \mathrm{~h}$ of isolation, play reduced the FpCD in the dark category $(t=-2.191$, d.f. $=14, P=0.046)$. In none of the other regions were effects of play observed in the different categories [light: $\mathrm{mHb}$ : $F_{\text {play }}(1,27)=1.859, \quad P=0.184 ; \quad 1 \mathrm{Hbm}: \quad F_{\text {play }}(1,28)=0.789$ $P=0.382 ; 1 \mathrm{Hbl}: F_{\text {play }}(1,28)=0.377, P=0.544 ;$ medium: $\mathrm{mHb}$ : $F_{\text {play }}(1,27)=0.758, \quad P=0.392 ; \quad 1 \mathrm{Hbm}: \quad F_{\text {play }}(1,28)=0.791$, $P=0.381 ; \quad 1 \mathrm{Hbl}: \quad F_{\text {play }}(1,28)=1.343, \quad P=0.256 ; \quad$ dark: $\mathrm{mHb}$ : $F_{\text {play }}(1,27)=0.186, \quad P=0.670 ; \quad$ lHbl: $\quad F_{\text {play }}(1,28)=0.595$, $P=0.447]$ (Fig. 4).

In summary, social isolation enhanced c-fos expression throughout the habenula. Social play behaviour reduced the number of dark c-fos-expressing cells in the $1 \mathrm{Hbm}$ after $24 \mathrm{~h}$ of social isolation. 

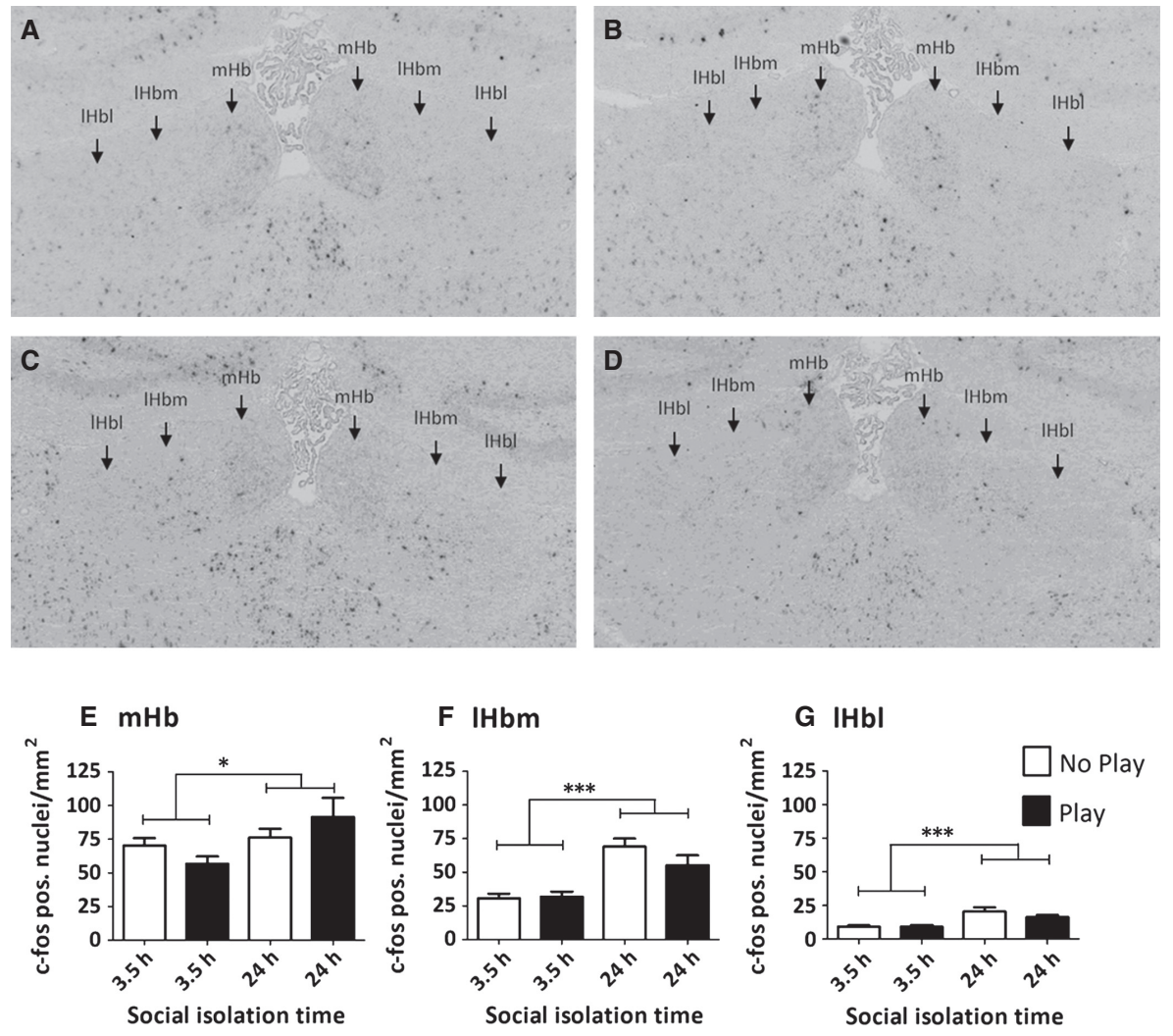

FIG. 3. Social isolation for $24 \mathrm{~h}$ enhances the cell density of c-fos-positive cells. The FpCD was determined in rats after 3.5 or $24 \mathrm{~h}$ of social isolation and subsequently receiving a play session (play; black bars) and in rats that were placed in the test cage without a partner (no play; white bars). Representative pictures of c-fos labelling after $3.5 \mathrm{~h}$ no play (A), $3.5 \mathrm{~h}$ play (B), $24 \mathrm{~h}$ no play (C), and $24 \mathrm{~h}$ play (D). The contrast of these images was enhanced for illustrative purposes (CorelDraw Graphics X5, contrast $+40 \%$, brightness $-25 \%$ ). Note that original images were used for the analysis. Quantification of c-fos-positive cells in the four groups in the $\mathrm{mHb}(\mathrm{E}), 1 \mathrm{Hbm}(\mathrm{F})$ and $1 \mathrm{Hbl}(\mathrm{G})$. Data are presented as mean $\pm \mathrm{SEM}$. $* P<0.05, * * * P<0.001$.

\section{Temporary inactivation of the habenula reduced social play behaviour}

To further investigate the role of the habenula in social play behaviour, this region was temporarily inactivated by local administration of B\&M. The effect of B\&M administration was investigated after both 3.5 and $24 \mathrm{~h}$ of social isolation (Fig. 5). The dose of $1.0 \mathrm{nmol} / 0.3 \mu \mathrm{L}$ baclofen and $0.1 \mathrm{nmol} / 0.3 \mu \mathrm{L}$ muscimol almost completely abolished the levels of pinning after $24 \mathrm{~h}$ of isolation $(t=4.808$, d.f. $=5, P=0.005)$ (Fig. 5A). In addition, this dose of $\mathrm{B} \& \mathrm{M}$ decreased pouncing $(t=4.074$, d.f. $=5, P=0.010)$ and reduced the total time spent on social play behaviour $(t=6.321$, d.f. $=5, P=0.002)$. In contrast, social exploratory behaviour was unaffected ( $t=-0.849$, d.f. $=5, P=0.435)$. These results indicate a specific effect of habenula inactivation on social play behaviour, without affecting non-playful social interactions.

As this dose of $\mathrm{B} \& \mathrm{M}$ profoundly reduced social play behaviour, a lower dose of B\&M $(0.3 \mathrm{nmol} / 0.3 \mu \mathrm{L}$ baclofen and $0.03 \mathrm{nmol} /$ $0.3 \mu \mathrm{L}$ muscimol) was also tested after $24 \mathrm{~h}$ of social isolation (Fig. 5A). This dose also reduced pinning $(t=3.177$, d.f. $=10$, $P=0.010)$ and total play duration $(t=3.804$, d.f. $=10, P=0.003)$, but did not affect pouncing $(t=1.662$, d.f. $=10, P=0.128)$. These results suggest that, at a lower dose, inactivation of the habenula specifically affected the responsiveness to social play initiations. Similar to the higher dose, this dose did not influence social exploration $(t=-1.616$, d.f. $=10, P=0.137)$.

As social isolation affected FpCD in the habenula (Figs 3 and 4 ), the effect of temporary inactivation of the habenula was also investigated after $3.5 \mathrm{~h}$ of social isolation, to establish whether the involvement of the habenula in social play depended on the duration of social isolation (Fig. 5B). After $24 \mathrm{~h}$ of social isolation, the lower dose of $\mathrm{B} \& \mathrm{M}$ profoundly reduced pinning, but not pouncing, whereas the higher dose of $\mathrm{B} \& \mathrm{M}$ almost completely blocked pinning, suggesting that the reduction in pouncing at this dose was secondary to the reduced responsiveness to play initiation. Therefore, only the lower dose of $\mathrm{B} \& \mathrm{M}(0.3 \mathrm{nmol} / 0.3 \mu \mathrm{L}$ baclofen and $0.03 \mathrm{nmol} / 0.3 \mu \mathrm{L}$ muscimol) was tested after $3.5 \mathrm{~h}$ isolation. Similar to what happened after $24 \mathrm{~h}$ of social isolation, $\mathrm{B} \& \mathrm{M}$ reduced pinning $(t=5.106$, d.f. $=10, P<0.001)$ and the total play duration $(t=4.668$, d.f. $=10, P=0.001)$, but not pouncing $(t=1.664$, d.f. $=10, P=0.127)$ or social exploration $(-1.837$, d.f. $=10, P=0.096)$. Interestingly, although levels of play are usually half-maximal and maximal, respectively, after social isolation for 3.5 or $24 \mathrm{~h}$ before the test (Niesink \& Van Ree, 1989; Vanderschuren et al., 1995, 2008), in this series of experiments, the absolute amounts of social play after $3.5 \mathrm{~h}$ of social isolation (Fig. 5B) were similar to those after $24 \mathrm{~h}$ of isolation (Fig. 5A). This is probably the result of interexperiment variation. Indeed, especially after intracranial surgery, the levels of social play that we observe can vary considerably but, in our experience, this variation has minimal influence on the effectiveness of drug treatments or intracranial manipulations (Trezza \& Vanderschuren, 2008b; Trezza et al., 2011b, 2012; van Kerkhof et al., 2013a). Therefore, we think that it is fair to conclude from these experiments (Fig. 5A and B) that the duration of social 
A $\mathrm{mHb}$

Light category

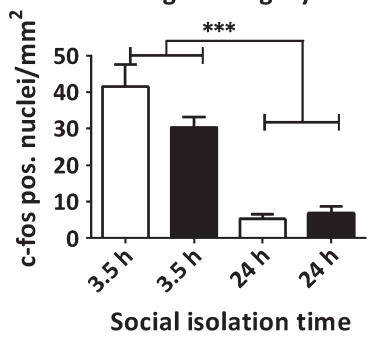

D IHbm

Light category

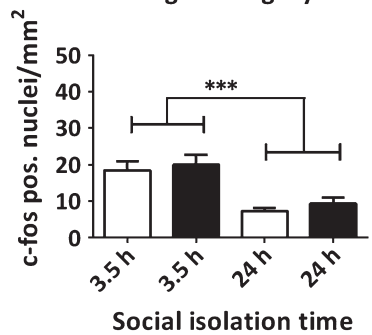

G IHbl

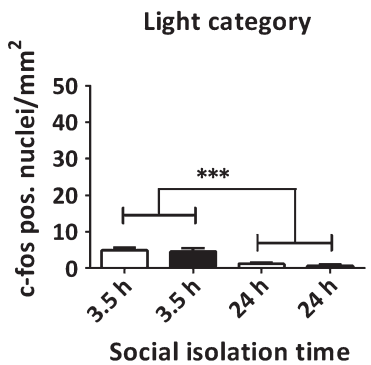

B $\mathrm{mHb}$

Medium category

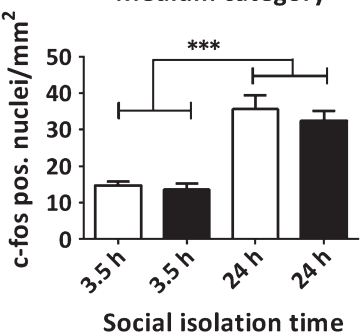

E IHbm

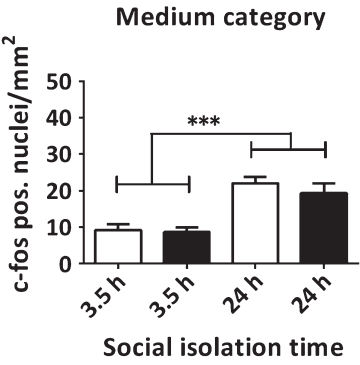

$\mathbf{H} \mathbf{I H b}$

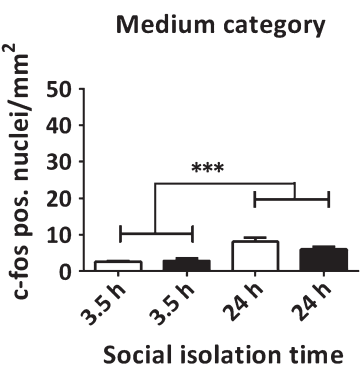

C $\mathrm{mHb}$

Dark category

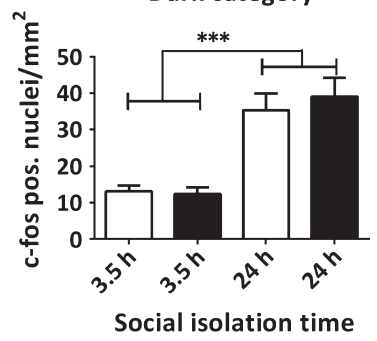

F IHbm

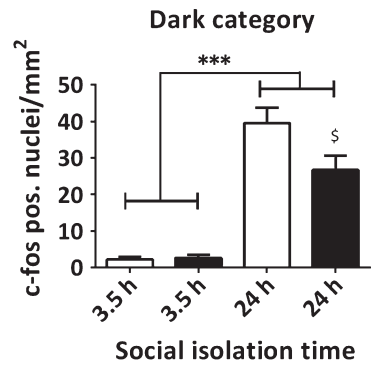

I |Hb|

Dark category

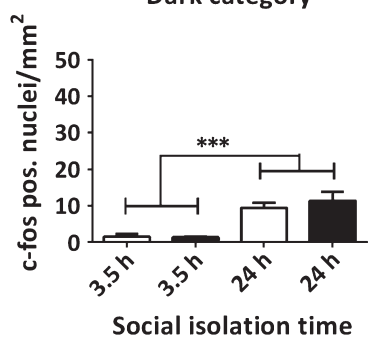

FIG. 4. Social isolation for $24 \mathrm{~h}$ reduces the cell density of light c-fos-positive cells, whereas it increases the cell density of medium and dark positive cells in the $\mathrm{mHb}(\mathrm{A}-\mathrm{C}), 1 \mathrm{Hbm}(\mathrm{D}-\mathrm{F})$, and $1 \mathrm{Hbl}(\mathrm{G}-\mathrm{I})$. Social play behaviour reduces the density of dark c-fos-positive cells after $24 \mathrm{~h}$ of social isolation in the $1 \mathrm{Hbm}$ (F). The FpCD was determined in rats after 3.5 or $24 \mathrm{~h}$ of social isolation and subsequently receiving a play session (play; black bars) and in rats that were placed in the test cage without a partner (no play; white bars). Data are presented as mean \pm SEM. $* * * P<0.0013 .5 \mathrm{~h}$ vs. $24 \mathrm{~h}$ of social isolation, ${ }^{\$} P<0.05$ play vs. no play group.

isolation had no major influence on the play-reducing effect of functional inactivation of the habenula. None of the B\&M doses tested influenced locomotor activity $\left[F_{\text {treatment }}(2.28)=1.390\right.$, $P=0.266]$ (Fig. 5C).

In summary, these results indicate that the inactivation of the habenula specifically affected social play behaviour, leaving locomotor activity and non-playful social investigation intact. Responsiveness to play solicitation, i.e. pinning, was more sensitive to habenula inactivation than the initiation of play, i.e. pouncing. Furthermore, the disruption of play by inactivation of the habenula was independent of the duration of social isolation.

\section{Discussion}

The present study is the first to report involvement of the habenula in social play behaviour in rats. Our data show that the habenula becomes activated after social isolation. This social isolation-induced activation is reduced in the $1 \mathrm{Hbm}$ after social play. In addition, pharmacological inactivation of the habenula suppressed social play behaviour.

\section{The habenula responds to social isolation}

In the present study, c-fos activity in the habenula was investigated after two periods of social isolation that have been shown to induce half-maximal and maximal levels of social play behaviour (Niesink \& Van Ree, 1989; Vanderschuren et al., 1995, 2008). Social isolation for $24 \mathrm{~h}$ enhanced the number of cells expressing c-fos relative to $3.5 \mathrm{~h}$ of social isolation, throughout the entire habenula. Previous studies, as well as our own observations, using c-fos as a neuronal activity marker have shown that the basal c-fos level in the habenula is low in naive animals (Wirtshafter et al., 1994; Zhang et al., 2005). It is therefore possible that, after $3.5 \mathrm{~h}$ of isolation, the levels of c-fos are enhanced compared with baseline, but to a lesser extent than after $24 \mathrm{~h}$ of isolation. This suggests that cellular activity in the habenula is a function of the duration of social isolation.

Activation of the habenula after social isolation may be related to its role in the processing of aversive information (Hikosaka, 2010). Indeed, stressful stimuli have been shown to enhance c-fos expression in the $1 \mathrm{Hb}$ (Wirtshafter et al., 1994) and to induce immune responses in the mHb (Cirulli et al., 1998; Sugama et al., 2002). In 
A $24 \mathrm{~h}$ social isolation
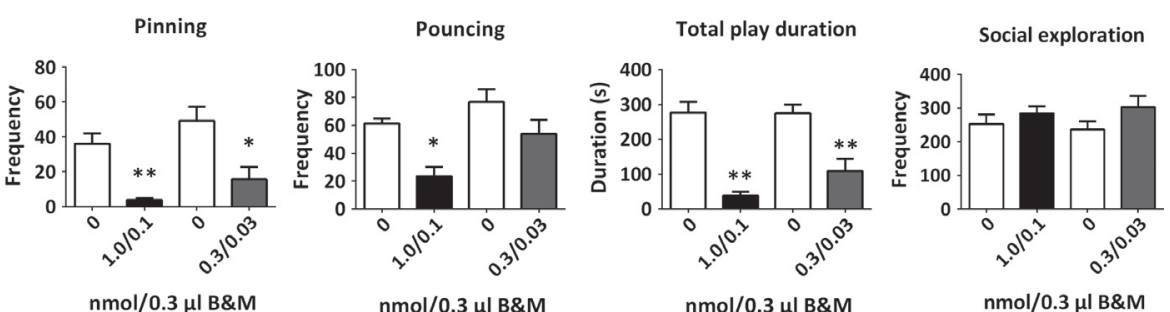

B $3.5 \mathrm{~h}$ social isolation
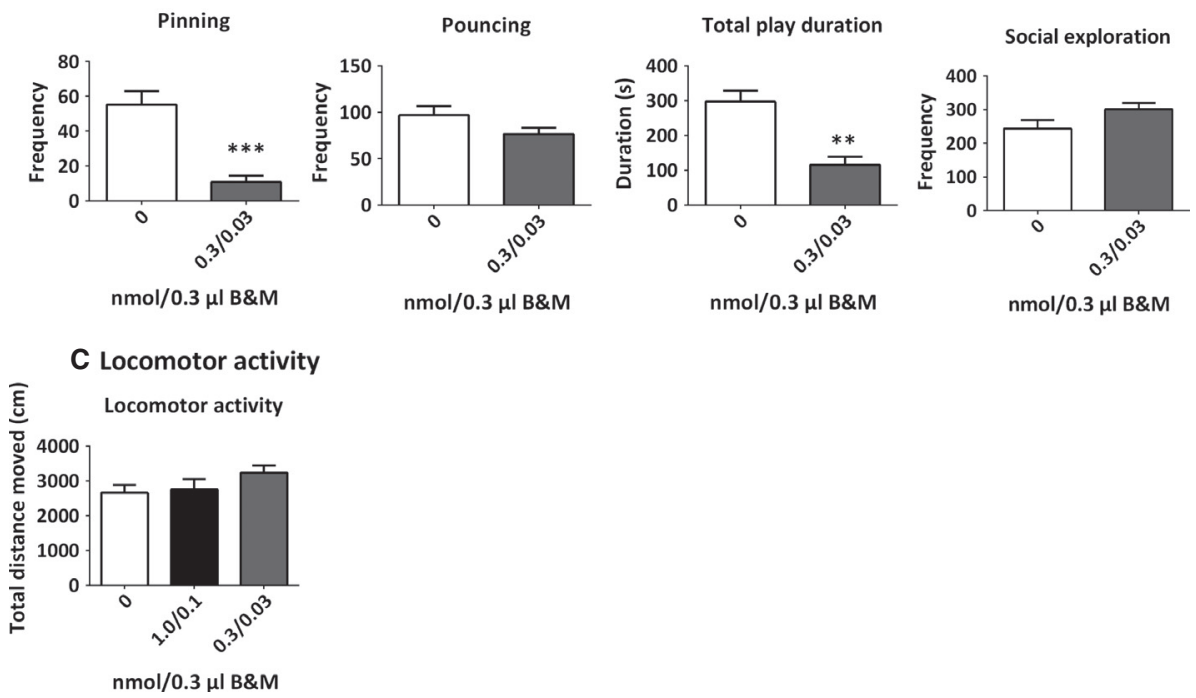

FIG. 5. Pharmacological inactivation of the habenula with $B \& M$ reduces social play after $24 \mathrm{~h}(\mathrm{~A})$ and $3.5 \mathrm{~h}$ (B) of isolation, but does not affect social exploration (A and B) or locomotor activity $(\mathrm{C})$. Saline $(0 \mathrm{nmol} \mathrm{B} \& \mathrm{M})$, white bars; $1.0 / 0.1 \mathrm{~B} \& \mathrm{M}$, black bars; 0.3/0.03 nmol B\&M, dark grey bars. Data are presented as mean \pm SEM. $* P<0.05, * * P<0.01, * * * P<0.001$ vs. saline $(0$ nmol B\&M $)$.

addition, neuronal activity in the $\mathrm{mHb}$ and $\mathrm{lHb}$ has been found to be enhanced in rat models of depression (Caldecott-Hazard et al., 1988; Shumake et al., 2003). It is therefore likely that in the present study the habenula was activated as a result of the negative emotional effects of social isolation.

The habenula is positioned as a key regulator of monoaminergic neurotransmission. Activation of the habenula results in decreased activity of dopaminergic and serotonergic neurons, and/or increased noradrenergic activity, via direct and indirect projections to the VTA, dorsal raphe nucleus and locus coeruleus, respectively (Stern et al., 1979; Kalén et al., 1989a,b; Lecourtier \& Kelly, 2007; Lecourtier et al., 2008). Recently, it has been shown that the projection of the $1 \mathrm{Hb}$ to the rostromedial tegmental nucleus, which in turn regulates dopamine activity via its inhibitory projections to the VTA and substantia nigra, signals aversive information (Hong et al., 2011; Lammel et al., 2012; Stamatakis \& Stuber, 2012). Therefore, activity in the habenula after social isolation may result in altered monoamine levels, which signal the affective states associated with social isolation and the modulation of subsequent social interaction.

\section{Social play reduces c-fos expression in the habenula after social isolation}

The opportunity to play reduced the number of darkly labelled c-fos-positive cells in the $1 \mathrm{Hbm}$ after $24 \mathrm{~h}$ of social isolation. The reduction in FpCD after play in animals isolated for $24 \mathrm{~h}$ may be related to the increase in c-fos expression as a result of social isolation. Social play behaviour is known to be highly rewarding (Vanderschuren, 2010; Trezza et al., 2011a). The experience of a positive social event or the termination of the negative situation associated with social isolation may therefore reduce the activity evoked by the aversive properties of social isolation in this part of the habenula. It is then reasonable to expect that the experience of social play behaviour has a larger effect on habenula activity after longer isolation periods, which is in keeping with our observations.

Interestingly, social play specifically reduced the FpCD in the $1 \mathrm{Hbm}$, whereas it did not affect c-fos levels in the $\mathrm{mHb}$ or $1 \mathrm{Hbl}$. These different habenula subregions are known to have distinct efferent and afferent connections, whereby the $1 \mathrm{Hb}$ has dense projections to monoamine-producing nuclei (Aghajanian \& Wang, 1977; Lecourtier \& Kelly, 2007; Jhou et al., 2009; Goncalves et al., 2012). More specifically, the $1 \mathrm{Hbl}$ mainly projects to the rostromedial tegmental nucleus, which provides a GABAergic input to the VTA and dorsal raphe nucleus, whereas the $1 \mathrm{Hbm}$ mainly projects directly to the VTA and dorsal raphe nucleus and has only sparse projections to the rostromedial tegmental nucleus (Kim, 2009; Goncalves et al., 2012). It has been hypothesized that the $1 \mathrm{Hbl}$ is involved in signalling aversive stimuli via the rostromedial tegmental nucleus-VTA pathway to inhibit activity of dopamine neurons (Hong et al., 2011; Lammel et al., 2012; Stamatakis \& Stuber, 2012), whereas the $1 \mathrm{Hbm}$ is part of a habenula-VTA feedback loop, because the $1 \mathrm{Hbm}$ directly projects to, and also receives direct inputs from, the VTA (Skagerberg et al., 1984; Goncalves et al., 2012). The experience of social play behaviour after $24 \mathrm{~h}$ of social 
isolation therefore alters the activity in the habenula-VTA loop, reflected by changes in $1 \mathrm{Hbm}$ activity.

The $1 \mathrm{Hb}$ is also implicated in regulating serotonin and noradrenaline neurotransmission. This may also be related to the effects of play on habenula c-fos levels, as these neurotransmitters are known to modulate social play behaviour (Vanderschuren et al., 1997, 2008; Homberg et al., 2007; Trezza et al., 2010; Siviy \& Panksepp, 2011; Siviy et al., 2011). It has recently been shown that signalling from the basal ganglia to the habenula in response to aversive stimuli is reduced by serotonin (Shabel et al., 2012), and that antidepressants reduce the c-fos response to stress in the $\mathrm{mHb}$ (Silva et al., 2012). Thus, the play-induced suppression of habenula activity may be mediated by serotonin.

In summary, the positive experience of social play behaviour may reduce habenula activity when the animal is in a negative emotional state as a result of social isolation, through altered dopamine or serotonin neurotransmission.

\section{Inactivation of the habenula reduces social play behaviour}

In the present study, we used local administration of a mixture of two GABA receptor agonists to temporarily inactivate the habenula (Martin \& Ghez, 1999; Majchrzak \& Di Scala, 2000; McFarland \& Kalivas, 2001; van Duuren et al., 2007). Pharmacological inactivation of the habenula decreased the frequency of pinning and the total play duration, whereas a higher dose of the agonists also reduced pouncing. The effect of habenula inactivation was specific for playful social behaviour, as neither social exploration nor locomotor activity was affected. The absence of an effect on general social interest is in keeping with the effects of lesions of the habenula, which were found not to impair social interaction in adult rats (Lecourtier et al., 2004). These results therefore suggest that, in young rats, the habenula is specifically involved in playful, rewarding social interactions.

The present study shows that the responsiveness to a playful solicitation is more sensitive to habenula inactivation than initiation of a playful interaction. Inactivation of the habenula reduced pinning, which is the response to a playful solicitation (Poole \& Fish, 1975; Panksepp \& Beatty, 1980; Pellis \& Pellis, 1987; Pellis et al., 1989), and, at a high dose of B\&M, pouncing (i.e. play solicitation) was also reduced. This reduction in pouncing is probably an indirect effect of near-complete abolishment of responsiveness to play solicitation after treatment with the higher dose of B\&M. The explanation resonates well with an older study that found that lesions of the habenula reduced the responsiveness to sexual solicitation in female rats, but not sexual initiative in male rats (Modianos et al., 1974). As our infusions covered both the $1 \mathrm{Hb}$ and $\mathrm{mHb}$ subnuclei, the alternative possibility that distinct subregions of the habenula, which are differentially sensitive to GABA receptor agonism, modulate different aspects of play cannot be ruled out. Our observation that habenula inactivation particularly reduced the responsiveness to play solicitation is not easily explained on the basis of the role of the habenula in signalling aversive information (Hikosaka, 2010). Rather, these findings suggest that habenula activity plays a role in the prolongation of a positive social interaction, such as sexual behaviour (Modianos et al., 1974) or social play (present study). Together, our data therefore implicate the habenula in the processing of social information, which can be of either positive (i.e. social play) or negative (i.e. social isolation) valence.

The habenula complex has direct efferent and afferent connections with regions that have previously been reported to be involved in social play behaviour, such as the thalamus and septum (Beatty et al., 1982; Siviy \& Panksepp, 1985, 1987; Lecourtier \& Kelly, 2007). In addition, the habenula is a key regulator of monoaminergic neurotransmission, and inactivation of the habenula is likely to interfere with this process. As mentioned above, manipulations of habenula signalling have been reported to alter dopamine (Lecourtier et al., 2008), serotonin (Stern et al., 1979; Kalén et al., 1989b; Yang et al., 2008) and noradrenaline neurotransmission (Kalén et al., 1989a,b). Numerous previous studies have indicated that a correct balance in monoaminergic activity is essential for the expression of social play behaviour (for reviews see Vanderschuren et al., 1997; Trezza et al., 2010; Siviy \& Panksepp, 2011). Therefore, it is likely that inactivation of the habenula disrupts social play behaviour via alteration of monoaminergic signalling and/or via its projection to other regions, such as the thalamus.

\section{Concluding remarks}

The present study indicates an important role for the habenula in the processing of positive (i.e. social play behaviour) and negative (i.e. social isolation) social information. These data enhance our knowledge of the neural mechanisms of social play behaviour. This is of great relevance in view of the importance of social play for behavioural development and the impairments in social play seen in child and adolescent psychiatric disorders. In addition, these findings contribute to our knowledge of the physiological role of the habenula in adaptive behaviour, extending its importance beyond the processing of aversive information.

\section{Acknowledgements}

This work was supported by the National Institute on Drug Abuse (grant R01 DA022628 to L.J.M.J.V.), Netherlands Organization for Scientific Research (NWO) Veni (grant 91611052 to V.T.) and Marie Curie Career Reintegration (grant PCIG09-GA-2011-293589 to V.T.). The authors have no conflict of interest to disclose.

\section{Abbreviations}

B\&M, baclofen and muscimol; DIG, digoxigenin; FpCD, c-fos-positive cell density; $1 \mathrm{Hb}$, lateral habenula; $1 \mathrm{Hbl}$, lateral habenula lateral part; $1 \mathrm{Hbm}$, lateral habenula medial part; $\mathrm{mHb}$, medial habenula; VTA, ventral tegmental area.

\section{References}

Aghajanian, G.K. \& Wang, R.Y. (1977) Habenular and other midbrain raphe afferents demonstrated by a modified retrograde tracing technique. Brain Res., 122, 229-242.

Alessandri, S.M. (1992) Attention, play, and social behavior in ADHD preschoolers. J. Abnorm. Child Psych., 20, 289-302.

Baarendse, P.J.J., Counotte, D.S., O’Donnell, P. \& Vanderschuren, L.J.M.J. (2013) Early social experience is critical for the development of cognitive control and dopamine modulation of prefrontal cortex function. Neuropsychopharmacol., 38, 1485-1494.

Baenninger, L.P. (1967) Comparison of behavioural development in socially isolated and grouped rats. Anim. Behav., 15, 312-323.

Beatty, W.W., Dodge, A.M., Traylor, K.L., Donegan, J.C. \& Godding, P.R. (1982) Septal lesions increase play fighting in juvenile rats. Physiol. Behav., 28, 649-652.

Bell, H.C., McCaffrey, D.R., Forgie, M.L., Kolb, B. \& Pellis, S.M. (2009) The role of the medial prefrontal cortex in the play fighting of rats. Behav. Neurosci., 123, 1158-1168.

Bolles, R.C. \& Woods, P.J. (1964) The ontogeny of behavior in the albino rat. Anim. Behav., 12, 427-441.

Caldecott-Hazard, S., Mazziotta, J. \& Phelps, M. (1988) Cerebral correlates of depressed behavior in rats, visualized using 14C-2-deoxyglucose autoradiography. J. Neurosci., 8, 1951-1961. 
Cirulli, F., Pistillo, L., De Acetis, L., Alleva, E. \& Aloe, L. (1998) Increased number of mast cells in the central nervous system of adult male mice following chronic subordination stress. Brain Behav. Immun., 12, 123-133.

Daenen, E.W., Wolterink, G., Gerrits, M.A.F.M. \& Van Ree, J.M. (2002) The effects of neonatal lesions in the amygdala or ventral hippocampus on social behaviour later in life. Behav. Brain Res., 136, 571-582.

van Duuren, E., van der Plasse, G., van der Blom, R., Joosten, R.N.J.M.A., Mulder, A.B., Pennartz, C.M.A. \& Feenstra, M.G.P. (2007) Pharmacological manipulation of neuronal ensemble activity by reverse microdialysis in freely moving rats: a comparative study of the effects of tetrodotoxin, lidocaine, and muscimol. J. Pharmacol. Exp. Ther., 323, 61-69.

Goncalves, L., Sego, C. \& Metzger, M. (2012) Differential projections from the lateral habenula to the rostromedial tegmental nucleus and ventral tegmental area in the rat. J. Comp. Neurol., 520, 1278-1300.

Higo, N., Oishi, T., Yamashita, A., Matsuda, K. \& Hayashi, M. (1999) Quantitative non-radioactive in situ hybridization study of GAP-43 and SCG10 mRNAs in the cerebral cortex of adult and infant macaque monkeys. Cereb. Cortex, 9, 317-331.

Hikosaka, O. (2010) The habenula: from stress evasion to value-based decision-making. Nat. Rev. Neurosci., 11, 503-513.

Hill, W.D., Arai, M., Cohen, J.A. \& Trojanowski, J.Q. (1993) Neurofilament mRNA is reduced in Parkinson's disease substantia nigra pars compacta neurons. J. Comp. Neurol., 329, 328-336.

Homberg, J.R., Schiepers, O.J.G., Schoffelmeer, A.N.M., Cuppen, E. \& Vanderschuren, L.J.M.J. (2007) Acute and constitutive increases in central serotonin levels reduce social play behaviour in peri-adolescent rats. Psychopharmacology, 195, 175-182.

Hong, S., Jhou, T.C., Smith, M., Saleem, K.S. \& Hikosaka, O. (2011) Negative reward signals from the lateral habenula to dopamine neurons are mediated by rostromedial tegmental nucleus in primates. J. Neurosci., 31, $11457-11471$.

Jhou, T.C., Geisler, S., Marinelli, M., Degarmo, B.A. \& Zahm, D.S. (2009) The mesopontine rostromedial tegmental nucleus: a structure targeted by the lateral habenula that projects to the ventral tegmental area of Tsai and substantia nigra compacta. J. Comp. Neurol., 513, 566-596.

Jordan, R. (2003) Social play and autistic spectrum disorders: a perspective on theory, implications and educational approaches. Autism, 7, 347-360.

Kalén, P., Lindvall, O. \& Björklund, A. (1989a) Electrical stimulation of the lateral habenula increases hippocampal noradrenaline release as monitored by in vivo microdialysis. Exp. Brain Res., 76, 239-245.

Kalén, P., Strecker, R.E., Rosengren, E. \& Björklund, A. (1989b) Regulation of striatal serotonin release by the lateral habenula-dorsal raphe pathway in the rat as demonstrated by in vivo microdialysis: role of excitatory amino acids and GABA. Brain Res., 492, 187-202.

van Kerkhof, L.W.M., Damsteegt, R., Trezza, V., Voorn, P. \& Vanderschuren, L.J.M.J. (2013a) Social play behavior in adolescent rats is mediated by functional activity in medial prefrontal cortex and striatum. Neuropsychopharmacol., 38, 1899-1909.

van Kerkhof, L.W.M., Trezza, V., Mulder, T., Gao, P., Voorn, P. \& Vanderschuren, L.J.M.J. (2013b) Cellular activation in limbic brain systems during social play behaviour in rats. Brain Struct. Funct., doi: 10.1007/ s00429-013-0558-y. [Epub ahead of print].

Kim, U. (2009) Topographic commissural and descending projections of the habenula in the rat. J. Comp. Neurol., 513, 173-187.

Lammel, S., Lim, B.K., Ran, C., Huang, K.W., Betley, M.J., Tye, K.M., Deisseroth, K. \& Malenka, R.C. (2012) Input-specific control of reward and aversion in the ventral tegmental area. Nature, 491, 212-217.

Lecourtier, L. \& Kelly, P.H. (2007) A conductor hidden in the orchestra? Role of the habenular complex in monoamine transmission and cognition. Neurosci. Biobehav. R., 31, 658-672.

Lecourtier, L., Neijt, H.C. \& Kelly, P.H. (2004) Habenula lesions cause impaired cognitive performance in rats: implications for schizophrenia. Eur. J. Neurosci., 19, 2551-2560.

Lecourtier, L., Defrancesco, A. \& Moghaddam, B. (2008) Differential tonic influence of lateral habenula on prefrontal cortex and nucleus accumbens dopamine release. Eur. J. Neurosci., 27, 1755-1762.

Lee, Y.A. \& Goto, Y. (2011) Neurodevelopmental disruption of cortico-striatal function caused by degeneration of habenula neurons. PLOS ONE, 6, e19450.

Majchrzak, M. \& Di Scala, G. (2000) GABA and muscimol as reversible inactivation tools in learning and memory. Neural Plast., 7, 19-29.

Manning, M.M. \& Wainwright, L.D. (2010) The role of high level play as a predictor social functioning in autism. J. Autism Dev. Disord., 40, 523-533.

Martin, J.H. \& Ghez, C. (1999) Pharmacological inactivation in the analysis of the central control of movement. J. Neurosci. Meth., 86, 145-159.
Matthews-Felton, T., Corodimas, K.P., Rosenblatt, J.S. \& Morrell, J.I. (1995) Lateral habenula neurons are necessary for the hormonal onset of maternal behavior and for the display of postpartum estrus in naturally parturient female rats. Behav. Neurosci., 109, 1172-1188.

McFarland, K. \& Kalivas, P.W. (2001) The circuitry mediating cocaineinduced reinstatement of drug-seeking behavior. J. Neurosci., 21, $8655-8663$.

Meaney, M.J., Dodge, A.M. \& Beatty, W.W. (1981) Sex-dependent effects of amygdaloid lesions on the social play of prepubertal rats. Physiol. Behav., 26, 467-472.

Modianos, D.T., Hitt, J.C. \& Flexman, J. (1974) Habenular lesions produce decrements in feminine, but not masculine, sexual behavior in rats. Behav. Biol., 10, 75-87.

Moller, P. \& Husby, R. (2000) The initial prodrome in schizophrenia: searching for naturalistic core dimensions of experience and behavior. Schizophrenia Bull., 26, 217-232.

Niesink, R.J.M. \& Van Ree, J.M. (1989) Involvement of opioid and dopaminergic systems in isolation-induced pinning and social grooming of young rats. Neuropharmacology, 28, 411-418.

Nordquist, R.E., Vanderschuren, L.J.M.J., Jonker, A.J., Bergsma, M., De Vries, T.J., Pennartz, C.M.A. \& Voorn, P. (2008) Expression of amphetamine sensitization is associated with recruitment of a reactive neuronal population in the nucleus accumbens core. Psychopharmacology, 198, $113-126$.

Palagi, E. (2006) Social play in bonobos (Pan paniscus) and chimpanzees (Pan troglodytes): implications for natural social systems and interindividual relationships. Am. J. Phys. Anthropol., 129, 418-426.

Panksepp, J. \& Beatty, W.W. (1980) Social deprivation and play in rats. Behav. Neural Biol., 30, 197-206.

Panksepp, J., Siviy, S.M. \& Normansell, L. (1984) The psychobiology of play: theoretical and methodological perspectives. Neurosci. Biobehav. R., 8, 465-492.

Panksepp, J., Normansell, L., Cox, J.F. \& Siviy, S.M. (1994) Effects of neonatal decortication on the social play of juvenile rats. Physiol. Behav., 56, 429-443.

Paxinos, G. \& Watson, C. (2007) The Rat Brain in Sterotaxic Coordinates. Elsevier Academic, London.

Pellis, S.M. \& McKenna, M.M. (1992) Intrinsic and extrinsic influences on play fighting in rats: effects of dominance, partner's playfulness, temperament and neonatal exposure to testosterone propionate. Behav. Brain Res., 50, 135-145.

Pellis, S.M. \& Pellis, V.C. (1987) Play-fighting differs from serious fighting in both target of attack and tactics of fighting in the laboratory rat Rattus norvegicus. Aggressive Behav., 13, 227-242.

Pellis, S.M. \& Pellis, V.C. (1998) Play fighting of rats in comparative perspective: a schema for neurobehavioral analyses. Neurosci. Biobehav. R., 23, 87-101.

Pellis, S.M. \& Pellis, V.C. (2009) The Playful Brain. OneWorld Publications, Oxford.

Pellis, S.M., Pellis, V.C. \& Dewsbury, D.A. (1989) Different levels of complexity in the play-fighting by muroid rodents appear to result from different levels of intensity of attack and defense. Aggressive Behav., 15, 297-310.

Pellis, S.M., Castaneda, E., McKenna, M.M., Tran-Nguyen, L.T. \& Whishaw, I.Q. (1993) The role of the striatum in organizing sequences of play fighting in neonatally dopamine-depleted rats. Neurosci. Lett., 158, 13-15.

Pellis, S.M., Hastings, E., Shimizu, T., Kamitakahara, H., Komorowska, J., Forgie, M.L. \& Kolb, B. (2006) The effects of orbital frontal cortex damage on the modulation of defensive responses by rats in playful and nonplayful social contexts. Behav. Neurosci., 120, 72-84.

Poole, T.B. \& Fish, J. (1975) Investigation of playful behavior in Rattus norvegicus and Mus musculus (Mammalia). J. Zool., 175, 61-71.

Potegal, M. \& Einon, D. (1989) Aggressive behaviors in adult rats deprived of playfighting experience as juveniles. Dev. Psychobiol., 22, 159-172.

Robbins, E., Baldino, F. Jr., Roberts-Lewis, J.M., Meyer, S.L., Grega, D. \& Lewis, M.E. (1991) Quantitative non-radioactive in situ hybridization of preproenkephalin mRNA with digoxigenin-labeled cRNA probes. Anat. Rec., 231, 559-562.

Rozen, S. \& Skaletsky, H.J. (2000) Primer3 on the WWW for general users and for biologist programmers. In Krawetz, S. \& Misener, S. (Eds), Bioinformatics Methods and Protocols: Methods in Molecular Biology. Humana Press, Totowa, pp. 365-386.

Schneider, M. \& Koch, M. (2005) Deficient social and play behavior in juvenile and adult rats after neonatal cortical lesion: effects of chronic pubertal cannabinoid treatment. Neuropsychopharmacol., 30, 944-957. 
Shabel, S.J., Proulx, C.D., Trias, A., Murphy, R.T. \& Malinow, R. (2012) Input to the lateral habenula from the basal ganglia is excitatory, aversive, and suppressed by serotonin. Neuron, 74, 475-481.

Shumake, J., Edwards, E. \& Gonzalez-Lima, F. (2003) Opposite metabolic changes in the habenula and ventral tegmental area of a genetic model of helpless behavior. Brain Res., 963, 274-281.

Silva, M., Aguiar, D.C., Diniz, C.R., Guimaraes, F.S. \& Joca, S.R. (2012) Neuronal NOS inhibitor and conventional antidepressant drugs attenuate stress-induced fos expression in overlapping brain regions. Cell. Mol. Neurobiol., 32, 443-453.

Siviy, S.M. \& Panksepp, J. (1985) Dorsomedial diencephalic involvement in the juvenile play of rats. Behav. Neurosci., 99, 1103-1113.

Siviy, S.M. \& Panksepp, J. (1987) Juvenile play in the rat: thalamic and brain stem involvement. Physiol. Behav., 41, 103-114.

Siviy, S.M. \& Panksepp, J. (2011) In search of the neurobiological substrates for social playfulness in mammalian brains. Neurosci. Biobehav. R., 35, $1821-1830$.

Siviy, S.M., Fleischhauer, A.E., Kerrigan, L.A. \& Kuhlman, S.J. (1996) D2 dopamine receptor involvement in the rough-and-tumble play behavior of juvenile rats. Behav. Neurosci., 110, 1168-1176.

Siviy, S.M., Deron, L.M. \& Kasten, C.R. (2011) Serotonin, motivation, and playfulness in the juvenile rat. Dev. Cogn. Neurosci., 1, 606-616.

Skagerberg, G., Lindvall, O. \& Björklund, A. (1984) Origin, course and termination of the mesohabenular dopamine pathway in the rat. Brain Res., 307, 99-108.

Spear, L.P. (2000) The adolescent brain and age-related behavioral manifestations. Neurosci. Biobehav. R., 24, 417-463.

Špinka, M., Newberry, R.C. \& Bekoff, M. (2001) Mammalian play: training for the unexpected. Q. Rev. Biol., 76, 141-168.

Stamatakis, A.M. \& Stuber, G.D. (2012) Activation of lateral habenula inputs to the ventral midbrain promotes behavioral avoidance. Nat. Neurosci., 15, $1105-1107$.

Stern, W.C., Johnson, A., Bronzino, J.D. \& Morgane, P.J. (1979) Effects of electrical stimulation of the lateral habenula on single-unit activity of raphe neurons. Exp. Neurol., 65, 326-342.

Stylianopoulou, E., Lykidis, D., Ypsilantis, P., Simopoulos, C., Skavdis, G. \& Grigoriou, M. (2012) A rapid and highly sensitive method of non radioactive colorimetric in situ hybridization for the detection of mRNA on tissue sections. PLOS ONE, 7, e33898.

Sugama, S., Cho, B.P., Baker, H., Joh, T.H., Lucero, J. \& Conti, B. (2002) Neurons of the superior nucleus of the medial habenula and ependymal cells express IL-18 in rat CNS. Brain Res., 958, 1-9.

Trezza, V. \& Vanderschuren, L.J.M.J. (2008a) Cannabinoid and opioid modulation of social play behavior in adolescent rats: differential behavioral mechanisms. Eur. Neuropsychopharm., 18, 519-530.

Trezza, V. \& Vanderschuren, L.J.M.J. (2008b) Bidirectional cannabinoid modulation of social behavior in adolescent rats. Psychopharmacology, 197, 217-227.

Trezza, V., Baarendse, P.J.J. \& Vanderschuren, L.J.M.J. (2009) Prosocial effects of nicotine and ethanol in adolescent rats through partially dissociable neurobehavioral mechanisms. Neuropsychopharmacol., 34, 2560-2573.
Trezza, V., Baarendse, P.J.J. \& Vanderschuren, L.J.M.J. (2010) The pleasures of play: pharmacological insights into social reward mechanisms. Trends Pharmacol. Sci., 31, 463-469.

Trezza, V., Campolongo, P. \& Vanderschuren, L.J.M.J. (2011a) Evaluating the rewarding nature of social interactions in laboratory animals. Dev. Cogn. Neurosci., 1, 444-458.

Trezza, V., Damsteegt, R., Achterberg, E.J.M. \& Vanderschuren, L.J.M.J. (2011b) Nucleus accumbens mu-opioid receptors mediate social reward. $J$. Neurosci., 31, 6362-6370.

Trezza, V., Damsteegt, R., Manduca, A., Petrosino, S., van Kerkhof, L.W.M., Pasterkamp, R.J., Zhou, Y., Campolongo, P., Cuomo, V., Di Marzo, V. \& Vanderschuren, L.J.M.J. (2012) Endocannabinoids in amygdala and nucleus accumbens mediate social play reward in adolescent rats. J. Neurosci., 32, 14899-14908.

Van den Berg, C.L., Hol, T., Van Ree, J.M., Spruijt, B.M., Everts, H. \& Koolhaas, J.M. (1999) Play is indispensable for an adequate development of coping with social challenges in the rat. Dev. Psychobiol., 34, $129-138$.

Vanderschuren, L.J.M.J. (2010) How the brain makes play fun. Am. J. Play, 2, 315-337.

Vanderschuren, L.J.M.J., Niesink, R.J.M., Spruijt, B.M. \& Van Ree, J.M (1995) Effects of morphine on different aspects of social play in juvenile rats. Psychopharmacology, 117, 225-231.

Vanderschuren, L.J.M.J., Niesink, R.J.M. \& Van Ree, J.M. (1997) The neurobiology of social play behavior in rats. Neurosci. Biobehav. R., 21, 309326.

Vanderschuren, L.J.M.J., Trezza, V., Griffioen-Roose, S., Schiepers, O.J.G., Van Leeuwen, N., De Vries, T.J. \& Schoffelmeer, A.N.M. (2008) Methylphenidate disrupts social play behavior in adolescent rats. Neuropsychopharmacol., 33, 2946-2956.

Veeneman, M.M.J., Boleij, H., Broekhoven, M.H., Snoeren, E.M.S., Guitart Masip, M., Cousijn, J., Spooren, W. \& Vanderschuren, L.J.M.J. (2011) Dissociable roles of mGlu5 and dopamine receptors in the rewarding and sensitizing properties of morphine and cocaine. Psychopharmacology, 214, 863-876.

Wirtshafter, D., Asin, K.E. \& Pitzer, M.R. (1994) Dopamine agonists and stress produce different patterns of Fos-like immunoreactivity in the lateral habenula. Brain Res., 633, 21-26.

Yang, L.M., Hu, B., Xia, Y.H., Zhang, B.L. \& Zhao, H. (2008) Lateral habenula lesions improve the behavioral response in depressed rats via increasing the serotonin level in dorsal raphe nucleus. Behav. Brain Res., 188, 84-90.

Zhang, F., Zhou, W., Liu, H., Zhu, H., Tang, S., Lai, M. \& Yang, G. (2005) Increased c-Fos expression in the medial part of the lateral habenula during cue-evoked heroin-seeking in rats. Neurosci. Lett., 386, 133-137.

Zhao, C., Fujinaga, R., Yanai, A., Kokubu, K., Takeshita, Y., Watanabe, Y. \& Shinoda, K. (2008) Sex-steroidal regulation of aromatase mRNA expression in adult male rat brain: a quantitative non-radioactive in situ hybridization study. Cell Tissue Res., 332, 381-391. 